\title{
SMART CITY DEVELOPMENT STRATEGY PROFILE: USE CASE MODELING BASED ON SIMPLICIAL COMPLEXES
}

\author{
Y. Berrou ${ }^{1,2}$, E. Soulier ${ }^{1,}{ }^{*}$, P. Calvez ${ }^{2}$, B. Birregah ${ }^{3}$, P. Vidal ${ }^{4}$, E. Dupont ${ }^{5}$, B. Carballa ${ }^{6}$, G. Blot ${ }^{7}$, M. Guery ${ }^{7}$ \\ ${ }^{1}$ Department of Technologies for Cooperation, Interaction, and Knowledge in Collectives, University of Technology of Troyes \\ (UTT), Troyes, France; eddie.soulier@utt.fr \\ ${ }^{2}$ Computer Science and Artificial Intelligence Laboratory, ENGIE Lab CRIGEN, Stains, France \\ ${ }^{3}$ Department of System Modelling and Dependability, UTT, Troyes, France \\ ${ }^{4}$ Urbanity Master, University of Le Havre Normandie, Le Havre, France \\ ${ }^{5}$ Research and Innovation Strategy, National Agency of Territories' Cohesion, Paris, France \\ ${ }^{6}$ Chronos Group, France \\ ${ }^{7}$ Data Nostra, France
}

\section{Commission IV}

KEY WORDS: Smart city, Urban sustainability, Use case, Simplicial complex, Data science

\begin{abstract}
:
According to three workshops organized as part of a study on public service delegation of data, use case definitions appeared to be a common issue for cities. To facilitate this step in city projects, one possibility is to define their profiles precisely and to compare these to their development strategies to highlight whether they are aligned, and eventually, to adjust the activities accordingly. In this context, a smart city profile model was developed based on the bibliometric analysis of smart cities in the work of (Mora and Deakin, 2019). Thereafter, a smart city model was developed based on the Smart Grid Architecture Model to aid in implementing the use cases, as presented in the work of (Gottschalk et al., 2017) and the IEC 62559-2 standard. Finally, four smart city profiles were identified and a profile characterization method was proposed using simplicial complexes. The results of the analysis of a smart city profile using this method enabled an in-depth understanding of the profile, which can aid cities in identifying new use cases to implement to be in line with their strategic development.
\end{abstract}

\section{INTRODUCTION}

The dream of creating an ideal city is far from new: from ancient Greece with Plato and his authoritarian vision (Mora and Deakin, 2019) to the present day with smart cities, many have attempted to share their vision of improving the city. Several definitions exist for explaining a smart city, but the majority of these mention the technology used, particularly information and communication technology (ICT), as a tool for enhancing the city (Silva et al., 2018; Yin et al., 2015).

Cities are composed of a system of systems (and thus, subsystems) that are constantly interacting with people (ISO $37105,2019)$ as well as the environment, their historic past and culture, and the administrative and legal framework. These interactions and relations that shape cities make them unique. Based on this assumption, it appears unrealistic to have only one model for every city, as well as to have a "universal smart city architecture" in practice, as mentioned in (Silva et al., 2018). Cities all have different needs owing to their inherent differences.

From November 2019 to January 2020, a study consisting of three workshops was conducted on the public service delegation of data. All of the cities involved in this study have managed smart city projects, and the definition of use cases appears to be a common issue. The cities represented in these workshops were very different, thereby emphasizing the need to define their profiles precisely to determine whether these are aligned with their development strategies, and eventually, to adjust their activities accordingly.

The aim of the current study was to be able to improve the coherence of smart city activities with respect to the city strategic development. To this end, a methodology was proposed to aid in the definition of use cases, which is often an issue in the implementation of smart cities. Thereafter, a method for computing a smart city profile was developed based on simplicial complexes. Profile characterization is essential in aiding the identification of use cases relevant to the city.

Section 2 of this paper provides a description of the workshops, followed by the development of the smart city profile model, based on the work of (Mora and Deakin, 2019) and their bibliometric analysis on smart city literature in Section 3. Use cases are covered in Section 4. Section 5 presents the simplicial complexes that were used to identify the city profiles, and an example of Paris is presented in Section 6.

\section{DESCRIPTION OF WORKSHOPS}

The abovementioned study, conducted by the French National Agency of Territories' Cohesion (ANCT) and the University of Technology of Troyes (UTT), in collaboration with ENGIE Lab CRIGEN CSAI, the University of Le Havre, and the Chronos Group, aimed to achieve two goals:

- to determine the state of the art of cities that are part of data projects where the public sector decides to work with the private sector; and

\footnotetext{
${ }^{*}$ Corresponding author
} 
- to analyze their organizational and economic models to promote territorial innovation.

Three workshops were organized ${ }^{1}$ : the first one presented six city cases, the second one analyzed statements and issues identified in the city cases, and the final one presented several digital solutions for the city needs and issues.

\subsection{City cases}

The cases presented during this workshop involved heterogeneous communities, from a small city of less than 1200 inhabitants (Prats-de-Mollo-la-Preste) to a region, to a metropolis or a capital, Paris (approximately 2,2 million inhabitants) (French National Institute for Statistics and Economic Studies, 2019). The cases are briefly described below, following the workshop running order.

La Rochelle, a medium-sized city, has proposed a "self-data" project. Voluntary citizens are offered a personal data warehouse where they can store data that they produce indirectly (e.g., geo-tracking, public transport, and carpool data). This is made possible according to the $20^{\text {th }}$ article of the European General Data Protection Regulation. The citizens can use their data or share them with the city, allowing for improved understanding of their mobility needs to take appropriate action.

The Tuba is a public/private association that brings together the Lyon Metropolis, companies, and start-ups, to develop innovative solutions for the city. The data used in the projects are provided by the local authorities and private actors. This helps citizens to improve their data acculturation, and provides citizens and companies with the opportunity to work together by "co-developing" user-centric solutions.

Because of the isolated location of Prats-de-Mollo-la-Preste, electricity transport represents a significant part of the energy bill expenditure that tends to increase every year. The desire to become $100 \%$ autonomous in energy from 2021 resulted in the creation of a company known as "Prats' EnR," joining together the town and an association of citizens. Its aim is to improve the electricity grid, manage the consumption peaks, and allow citizens to follow and adjust their consumption.

The Nice Côte d'Azur Metropolis created a data warehouse where all of the collected data (regarding aspects such as security, health, the environment, energy, mobility, and eadministration) are stored and structured. The city uses the data internally to gain efficiency and to provide better quality services, but also trades data with private companies when the project is considered to be beneficial for the city and its citizens.

In 2015, Paris launched an innovation program known as "DataCity Paris," which aims to develop and experiment innovative solutions based on collaboration among the local authority, large companies, start-ups, and urban data providers. Every year, several projects are selected to develop concrete solutions for city issues based on data sourced by different actors.

Finally, the former Languedoc-Roussillon region, now merged into the Occitanie region, created an association in 1994 to share the geographical data acquisition cost. Since 2016 and with the obligation to place non-sensitive public data online, the region has extended its missions to share knowledge, support

\footnotetext{
${ }^{1}$ The workshops will be the subject of a publication by the
} ANCT in 2021. the opening of public data with local authorities, and obtain and make available data and databases.

\subsection{Challenges encountered}

Possible issues and challenges were discussed during the second workshop by three academic researchers in geography, an expert in mobility solutions, and the Prats-de-Mollo-la-Preste project coordinator.

Since the publication of the French law for a "digital republic" in 2016, the local authorities of at least 3500 inhabitants must open their data if they are not personal or confidential. However, many local authorities face the problem of data acculturation. Public services generally do not have the budget to hire data specialists. Moreover, the differences in the perception and expectations potentially involving data among the stakeholders are important.

This legal framework provides local authorities with the opportunity to enlarge their data skills. Eventually, three types of territories appear to emerge: the leaders; the followers, imitating the leaders or applying the laws strictly; and those who take a "wait-and-see approach," who do not want to or cannot treat data.

Territories may be in co-opetition, particularly those that wish to be leaders. The motivation to distinguish oneself may emerge, sometimes led by more of an investment in the design than in the content. Public dashboards can also be developed, thereby providing public access to key performance indicators. Although it may be interesting to highlight several issues and indicator evolutions, these are generally quantitative. As noted by (Green, 2019), focusing on efficiency and measures for problems such as traffic efficiency may lead to missing the possible side-effects on citizens.

Local authorities may associate with private companies to help with their data project and reduce the cost, whether this regards human investments, material investments or the costs inherent to the data.

Although public and private sectors frequently cooperate, the possible lack of data knowledge may lead to governance and sovereignty issues: public services must be careful about the precise definition of the project, the benefits for the city and the citizens who own the data, where the data are transited, and where the data centers are located and data processing take place. Moreover, data are valuable and may be sensitive: if the public sector requires data to implement a project, private companies may be reluctant to sell their data as they are concerned with losing profits. Furthermore, the public sector may not wish to share their data owing to concerns regarding what the company could do with the data.

Therefore, a trust issue may exist between the public sector and private companies, as well as citizens. New services or technologies that are developed to reduce a problem are sometimes regarded with suspicion by citizens or are simply not used by them. This may also be owing to the problem of acculturation of the population, leading to an inclusion issue and feelings of disengagement.

Local authorities should thus have an economic model and consider the valorization of the data and the project.

Another issue faced by local authorities is the interoperability of their data: it can be challenging for data originating from various services to be interoperable, owing to a lack of expertise and knowledge. Moreover, no official standard for formatting data exists, except for geographical ones following the 
European INSPIRE Directive that came into force in 2007. Thus, every local authority structures their data individually, which can make future cooperation difficult.

Finally, environmental issues may emerge. Although data projects can have a positive impact by monitoring electricity consumption or can support citizens in selecting transport modes that lead to lower $\mathrm{CO}_{2}$ emissions, the question of the environmental impact of data treatment and storage remains, as well as the use of sensors to capture data. Territories exhibit different maturity levels in terms of considering such issues in their projects. For example, in the DataCity project, the Paris city manages to reuse their sensors to capture data and focuses on the areas where the sensors will be located. Cities are also considering real data needs, so as not to store useless data. Therefore, local authorities must arbitrate on how data is collected, and the volume and content of the data.

\subsection{Best practices}

The third workshop presented various best practices, some of which responded to issues evocated in the second workshop. The workshop included IBM, a representative from Le Havre Seine Metropolis, the GFI group, GrDF, and Lexcity Avocats.

One means of addressing the issue of citizen participation in data projects could be to adapt the project to the population, as implemented by Nice Metropolis: composed of a large city surrounded by smaller ones including villages, the population age and proficiency in digital tools are not uniform, and solutions such as apps will not be developed in the same manner. Likewise, the city of Le Havre has implemented "informational buses" that travel to cities to teach and inform the population, particularly senior citizens. Enabling citizens to participate in the elaboration of projects can also help to improve the later acceptability of these projects. Allowing future users to participate may also aid in the design and increase the usefulness.

The "shared data" concept can allow public and private actors to produce, use, and share data. Moreover, deals between public and private sectors can be established, allowing data sharing in exchange for services. This can promote local involvement in the data for the common good.

Data sharing may also help to reduce costs, particularly those regarding storage, and energy consumption.

Data can be used to save money; for example, by optimizing street lighting, subsequently aiding in developing other services.

Finally, most design methodologies for smart city strategies face use case issues, because these constitute the starting point of any project.

These three workshops revealed use case characterization to be of the utmost importance for cities, and enriched the descriptor list used in the computation (Section 5).

\section{CITY PROFILE MODELING}

(Mora and Deakin, 2019) analyzed the state of the art of smart cities, assuming that a city is smart when an ICT platform exists that provides solutions to reach urban sustainability.

From their bibliometric analysis of documents published between 1992 and 2012, two main groups emerged: one that is techno-centric and one that advocates a more holistic approach to smart city development, both of which are ICT-driven. A second literature analysis from 1992 to 2018 led the authors to identify four main dichotomies, or eight hypotheses, as presented in Table 2. These hypotheses were tested with the analysis of four European smart cities: Amsterdam, Barcelona, Helsinki, and Vienna, which are considered as "leading examples," to identify the "strategic principles" followed. The analysis of numerous qualitative data led to the identification of a first database of city activities. A coding process was used to enrich the first database and to create a second one containing the entities associated with the activities. Other actions, such as research on citizen participation, enriched the databases.

Three classification systems were elaborated, as indicated in Table 1. The classification system relating to application domains resulted from the "services and applications" category of the first classification system. The analysis of the activity categories and application domains helped to test the hypotheses of dichotomies 1,2 and 4 ; the classification of the actors or entities was related to dichotomy 3 .

\begin{tabular}{|c|c|c|}
\hline $\begin{array}{l}\text { Activity } \\
\text { category }\end{array}$ & Application domains & $\begin{array}{l}\text { Actor } \\
\text { category }\end{array}$ \\
\hline $\begin{array}{l}\cdot \text { Community } \\
\text { building } \\
\text { - Strategic } \\
\text { framework } \\
\text { - Services and } \\
\text { applications } \\
\text { - Digital } \\
\text { infrastructure }\end{array}$ & 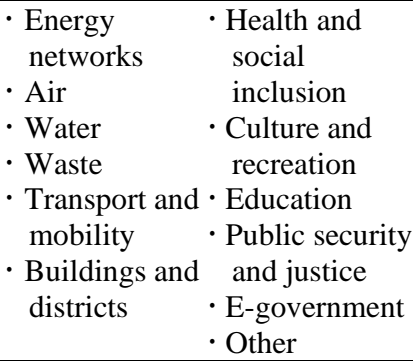 & $\begin{array}{l}\cdot \text { Industry } \\
\cdot \text { - Research } \\
\cdot \text { - Government } \\
\cdot \text { Civil society } \\
\cdot \text { Other }\end{array}$ \\
\hline
\end{tabular}

Table 1 . Three classification systems of smart city activities (Mora and Deakin, 2019)

Their analysis helped to identify best practice choices leading to strategic principles that European smart cities could apply for their decision-making processes.

Table 2 presents descriptions of the dichotomies, hypotheses, and strategic principles.

\begin{tabular}{|l|l|l|}
\hline Dichotomy & Hypothesis & Strategic principle \\
\hline $\begin{array}{l}\text { (1) Technology- } \\
\text { led or holistic }\end{array}$ & $\begin{array}{l}\text { Technology-led } \\
\text { strategy }\end{array}$ & $\begin{array}{l}\text { Look beyond } \\
\text { technology }\end{array}$ \\
\cline { 2 - 3 } & Holistic strategy & \\
\hline $\begin{array}{l}\text { (2) Double or } \\
\text { quadruple helix }\end{array}$ & $\begin{array}{l}\text { Two-helix model } \\
\text { of collaboration }\end{array}$ & $\begin{array}{l}\text { Move towards a } \\
\text { quadruple-helix } \\
\text { collaborative model }\end{array}$ \\
\cline { 2 - 3 } & $\begin{array}{l}\text { Four-helix model } \\
\text { of collaboration }\end{array}$ & $\begin{array}{l}\text { Combine top-down and } \\
\text { bottom-up }\end{array}$ \\
\cline { 2 - 2 } $\begin{array}{l}\text { (3) Top-down } \\
\text { or bottom-up } \\
\text { Build a strategic } \\
\text { framework }\end{array}$ \\
\cline { 2 - 3 } & $\begin{array}{l}\text { Top-down } \\
\text { approach }\end{array}$ & $\begin{array}{l}\text { Establish a smart city } \\
\text { accelerator to boost } \\
\text { digital transformation }\end{array}$ \\
\cline { 2 - 3 } & $\begin{array}{l}\text { Bottom-up } \\
\text { approach }\end{array}$ & $\begin{array}{l}\text { Mdopt integrated } \\
\text { intervention logic }\end{array}$ \\
\cline { 2 - 3 } $\begin{array}{l}\text { (4) Mono-dimensional } \\
\text { dimensional or } \\
\text { integrated }\end{array}$ & $\begin{array}{l}\text { Integrated } \\
\text { intervention logic }\end{array}$ & \\
\hline
\end{tabular}

Table 2. Dichotomies, hypotheses, and strategic principles identified by (Mora and Deakin, 2019)

The relations among the variables identified by Mora and Deakin were not sufficiently explicitly characterized. Thus, we present a new conceptual model of smart city development for urban sustainability, based on the work of Mora and Deakin, as 
illustrated in Figure 1. To reach urban sustainability, the city activities must be aligned with its development strategy. This can be achieved directly or by following strategic principles which will give insights for the implementation of modification of activities. Thus, the city activities should be characterized, and can be distributed in different categories (Table 1). Activities relating to the "service and application" category are subsequently categorized into the "application domains." The organization types involved in each activity are determined. These categories lead to the four dichotomies (Table 2): the strategy type (dichotomy 1), approach type (dichotomy 2), intervention logic type (dichotomy 3 ), and collaboration model type (dichotomy 4). The repartitioning of the activities across the dichotomies should be aligned with the development strategy.

The collaboration model type plays an important role, as the actors involved in smart city projects indirectly guide the implementation of activities, thus impacting the development strategy. However, managing many different actors can be difficult. As mentioned by (Cohen et al., 2016), "tensions can arise" in a city when it has to "[manage] an ecosystem of third parties".

The above builds the foundation for the characterization of a smart city profile. However, the work of Mora and Deakin was driven by an ICT approach and based on the idea that a city has to implement mainly ICT solutions to be smart.

Other city development models exist, such as urban models. For example, (van der Wusten, 2016) presented several urban models and their typology. Wusten distinguished five model categories that can be divided into three groups: (1) the initial model, supported by the International Congresses of Modern Architecture and Le Corbusier in the early 20th century, whereby the city is presented under its functional aspects and the main human activities are delimited in specific zones; (2) models focusing on the aspects of the city that are considered as the most important; and (3) models that consider the city in its entirety, but from the social perspective; that is, a development model that aims to enhance the local urban society.

We opted to focus on smart city development models, although urban models could be analyzed in future work.

\section{MODELING USE CASES}

To define a proper use case can be difficult, as it was mentioned several times during the workshops.

In 2015, a standard of the International Electrical Commission on use case methodology for complex systems was released (IEC 62559-2, 2015), which focused on power systems, and was followed in 2017 by a book describing how to apply this standard to smart grids (Gottschalk et al., 2017) via the Smart Grid Architecture Model (SGAM), developed by the Smart Grids Coordination Group (CEN-CENELEC-ETSI, 2012) The SGAM is a three-dimensional model composed of five vertical layers (the business, function, information, communication, and component layers), inspired by the interoperability layers defined by the GridWise Architecture Council (GWAC, 2008). Each layer has two axes: one for the zones representing the hierarchical model of power system management (from market to process) and another for the domains describing the electrical energy conversion chain (from generation to consumption).

In software engineering, use cases are scenarios that aim to achieve a goal. They describe a system and its functional requirements, as well as the interactions between the actors (human or not) and activities to be implemented. The process of describing these in a structured manner is known as Use Case Methodology, which led to the Use Case Template (IEC 62559$2,2015)$. The SGAM enables the use cases to be represented in accordance with the Use Case Template. The architecture layers and axes make it possible to map the different viewpoints and interactions according to the GWAC interoperability layers (Gottschalk et al., 2017; GWAC, 2008).

The attempt to create a Smart City Model based on the SGAM is presented in Figure 2.

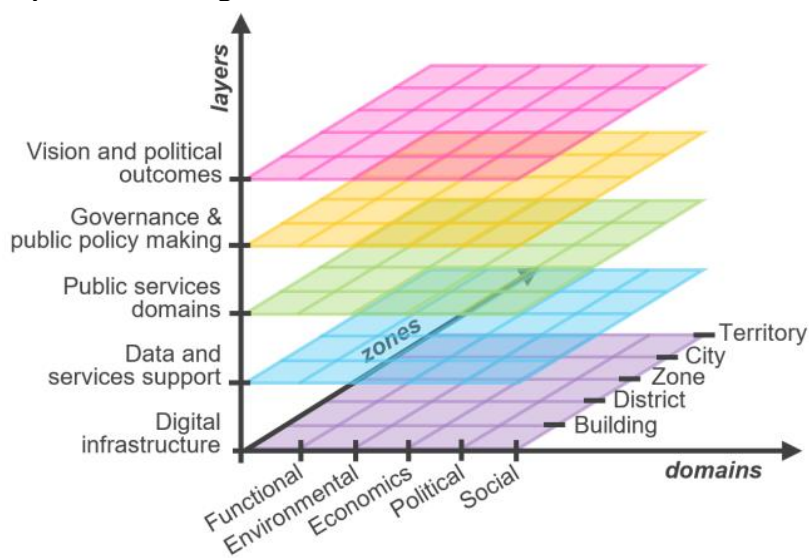

Figure 2. Smart City Model architecture

In the same manner as the SGAM, the layers are intended to achieve interoperability among the different systems (in a broad sense), from the vision and political outcome to the digital infrastructure of the smart city. The public service domains layer is composed of ten domains: transport and mobility, energy, waste, water, housing, buildings, government,

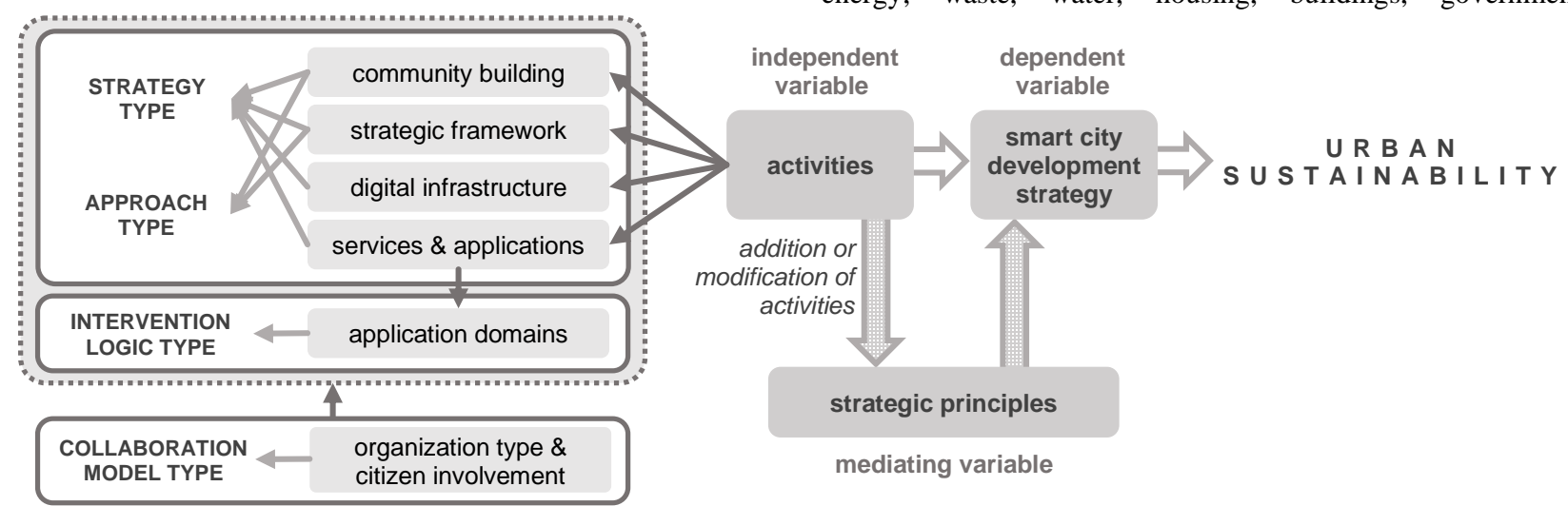

Figure 1. Conceptual model of smart city development for urban sustainability (created from Mora and Deakin, 2019) 
environmental, social, and quality of life, based on the classification of Mora and Deakin. The "zones" axis refers to the different scales to which the use case scenario will apply. The main city domains are represented on the "domains" axis.

The smart city entities and their relationships can be represented in the Smart City Model, as well as the use cases. For example, a city government may wish to enhance the safety of a specific district. Taking the mixed-up approach (Gottschalk et al., 2017), the entities are then mapped into the digital infrastructure. In our case, safety could fall under the functional domain if the solution requires the installation of a camera network (but it could be viewed as a political domain, with the deployment of policy officers). The intermediate layers can be developed from this intersection (functional and district).

The Smart City Model can subsequently be linked to the conceptual model of the smart city development. The process described hereinafter as well as in Figure 3 was inspired by Figure 1.1 of (Gottschalk et al., 2017). Starting from the initial state of the smart city, with all of its existing activities, the smart city profile can be determined using the computation process described in the following section. Its profile can aid in identifying certain gaps (step 1 in Figure 3), which can be linked to a strategic principle to reach the desired outcome. Once the strategic principle is identified, new use cases are developed (step 2). Thereafter, these new use cases must be implemented in the smart city model (step 3), allowing the identification of which actors must be involved and to which public service domains it refers. Eventually, the smart city activity portfolio is modified, whether by modifying existing activities or creating new ones.

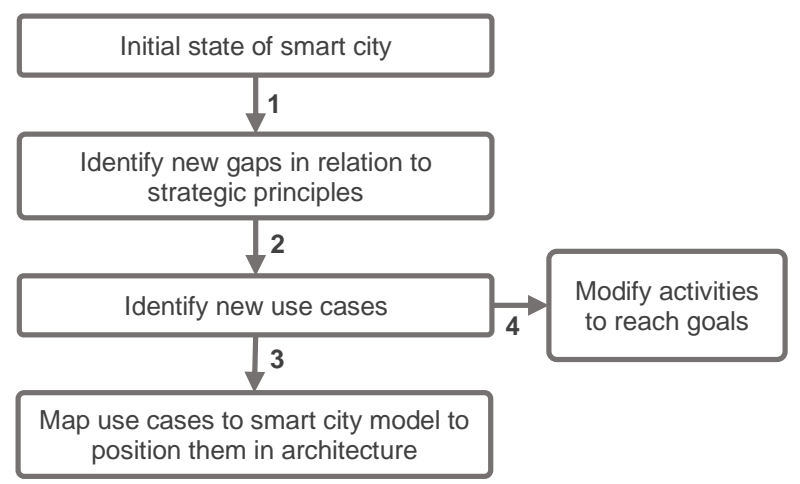

Figure 3. Identification and mapping of use cases inspired by (Gottschalk et al., 2017)

\section{APPLICATION}

\subsection{Profiles and descriptors}

Whereas (Mora and Deakin, 2019) identified smart city profiles from a bibliometric analysis and statistical approach, our proposition is based on data science and the topological approach.

As mentioned in Section 3, the authors distinguished two main groups: techno-centric and holistic, both of which are ICTdriven and can be assimilated into a smart city profile.

To take into account other smart city profiles, we added two other types. The first is characterized by the social aspect. As advocated by (Green, 2019), a city can be smart even without systematically using technology to solve its problems. According to Green, cities and their urban life should not be viewed as "something to optimize," even though technology may help. The social profile can be described by its propensity to promote democratic values, taking into account the heterogeneity of the citizens to address social needs in line with the specific population needs. Within this profile, problems are regarded as a whole and technology may be only one possible solution.

The second profile we added is between the social and holistic profiles. Cities that can be associated with this profile consider social and human issues as essential, and view technology as a tool to address these.

Thus, we propose retaining four ideal-type profiles: the technocentric, techno-social-centric (holistic), socio-technical-centric, and social-centric profiles.

A list of descriptors linked to each profile has been created, as shown in Table 3. Most of these descriptors originated from the sub-categories in Figure 1. They were completed by the descriptors identified from the workshops described in Section 2 and by the characteristics of the Smart Enough City from (Green, 2019). The optional links (light grey) represent the descriptors related to a specific profile but with significant impact thereon. They are computed in the same manner as the others, the distinction being made during the results analysis.

\begin{tabular}{|c|c|c|}
\hline \begin{tabular}{l|l|l|l|}
$\mathbf{P 1}$ & $\mathbf{P 2}$ \\
\end{tabular} & \begin{tabular}{|l|l|l|l|} 
P3 & P4 \\
\end{tabular} & Descriptors \\
\hline & & actor: government \\
\hline & & actor: industrial \\
\hline & & actor: research \\
\hline & & actor: civil society \\
\hline & & development of application or service \\
\hline & & application domain: transport and mobility \\
\hline & & application domain: energy \\
\hline & & application domain: waste \\
\hline & & application domain: water \\
\hline & & application domain: housing \\
\hline & & application domain: buildings \\
\hline & & application domain: government \\
\hline & & application domain: environment \\
\hline & & application domain: social \\
\hline & & application domain: quality of life \\
\hline & & no development of service or application \\
\hline & & development of data platform or infrastructure \\
\hline & & citizen participation at beginning \\
\hline & & citizen participation in middle \\
\hline & & citizen participation at end \\
\hline & & no citizen participation \\
\hline & & promote citizen engagement \\
\hline & & promote public awareness and digital literacy \\
\hline & & $\begin{array}{l}\text { stimulate user-driven innovation and community- } \\
\text { led urban development }\end{array}$ \\
\hline & & $\begin{array}{l}\text { improve understanding of smart city development } \\
\text { and benefits of ICT-driven approach }\end{array}$ \\
\hline & & other community building \\
\hline & & no community building \\
\hline & & roadmap, program, action plan \\
\hline & & $\begin{array}{l}\text { workgroups managing general course of smart } \\
\text { city development }\end{array}$ \\
\hline & & evaluation measures of results and progress \\
\hline & & other strategic framework \\
\hline & & no strategic framework \\
\hline & & address complex problems \\
\hline & & address social needs and advance policy \\
\hline
\end{tabular}




\begin{tabular}{|l|l|l|l|}
\hline & & & promote democratic values \\
\hline & & & $\begin{array}{l}\text { use of public data } \\
\text { make public data actionable }\end{array}$ \\
\hline & & & \\
\hline & & & taking into account those in need \\
\hline
\end{tabular}

Table 3. Descriptors and their related profiles, with P1: technocentric; P2: techno-social-centric; P3: socio-technical-centric; P4: social-centric. The dark grey cases represent a strong link between the descriptor and profile, the light grey cases represent an optional link, and the white cases represent no significant link

\subsection{Computational model}

Each city is different and is shaped by multiple factors, such as its history, geography, or activities. Our approach involves evaluating smart city profiles based on how their activities are related to descriptors.

Relational simplices make it possible to study n-ary relations among sets, which can be structured, leading to non-partitive hierarchical levels. Relational simplices enable the multidimensionality of relations among entities to be calculated and are used to study complex systems (Atkin, 1974).

(Mora and Deakin, 2019) conducted a deep bibliometric analysis, followed by a statistical analysis of European city activities, computing the percentage share for each category to identify the strategic principles followed. However, their statistical analysis did not enable a detailed analysis of city profiles, a fortiori if the city does not exactly match one profile. As far as we know, simplices appear to provide a unique means of analyzing the multidimensionality aspects in cities: they allow the relations between descriptors and one or more profiles to be studied, eventually leading to an even more detailed profile.

Simplices can be visually represented by polyhedra. Considering $n$ elements $x_{1}, x_{2}, \ldots, x_{n}$ of a set $\mathrm{X}$, this subset can be viewed as the polyhedron vertices, all of which are linked by a relation $R$. The dimension of the relational simplex is given by the number of vertices it contains minus one (Johnson, 2012). According to an example provided by (Johnson, 2014), the four main hobbies of a person can be viewed as a relational simplex of dimension 3 (and visually, by a tetrahedron), with the vertices being the hobbies and the entire tetrahedron representing the person. Polyhedra that share $p$ vertices are said to be $q$-near, with $q=p$-1, which means that they have a "face" of dimension $q$ in common. Continuing with the above example, two persons sharing three hobbies (vertices) share a $q$ dimensional face of dimension 2 of their associated polyhedron, and they are 2-near. Two simplices - or polyhedra - are said to be $q$-connected if one or more $q$-near polyhedra exist between them, and several simplices that are $q$-connected form a simplicial complex, denoted by $\mathrm{KY}(\mathrm{X}, \mathrm{R})$, where $\mathrm{X}$ is the set of vertices. The opposite relation can also be analyzed, namely $\mathrm{K}_{\mathrm{X}}\left(\mathrm{Y}, \mathrm{R}^{-1}\right)$. Analyzing these structures consists of identifying the -connected components for each dimension of the simplicial complex, which is known as Q-analysis, a method introduced by (Atkin, 1977, 1974, 1972). Figure 4 depicts three connected simplices.

To perform calculations on simplices, an application named Hype was conceived by the UTT laboratory, financed by ENGIE Lab CRIGEN CSAI, and developed by Data Nostra, a start-up specializing in data science. The main objective of Hype is to provide a model of the simplicial complexes and perform Q-analysis. Visualization tools and graph traversal are also provided.

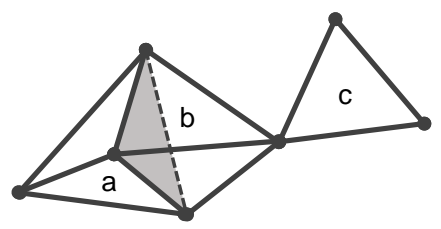

Figure 4. Three simplices of dimension $3(a$ and $b$ ) and $2(c)$. Simplices $a$ and $b$ are 2-near because they share a face; simplices $b$ and $c$ are 0 -near because they share one vertex; simplices $a$ and $c$ are 0 -connected

The Q-analysis algorithm used consists of three steps: (1) the dimensions are computed for each simplex; (2) the proximity is computed for each simplex by counting the number of vertices in common; (3) for each $q$ dimension and each simplex, the algorithm determines which simplices can be reached. Thus, each simplex has a set with its associated simplices, allowing the components (that is, groups of connected simplices at dimension $q$ ) to be found if there are disjoint sets.

A computation with simplices requires the identification of related sets. In our case, we have the set of activities that are considered as the vertices (columns) and the set of descriptors that are considered as the simplices (rows). An incidence matrix presenting the relations between the descriptors and activities is constructed, representing the simplicial complex of the city profile. It is filled in with 1 when the activity has the descriptor, and 0 otherwise. Table 4 displays part of the matrix used for the example developed in the next section.

\begin{tabular}{|l|c|c|c|c|}
\hline \multicolumn{1}{|c|}{ R: has descriptors } & ACT 0 & ACT 1 & ACT 2 & ACT 3 \\
\hline actor: government & 1 & 1 & 1 & 1 \\
\hline actor: industrial & 1 & 1 & 1 & 1 \\
\hline actor: research & 0 & 0 & 0 & 0 \\
\hline actor: civil society & 0 & 0 & 0 & 0 \\
\hline $\begin{array}{l}\text { development of } \\
\text { application or service }\end{array}$ & 0 & 1 & 1 & 1 \\
\hline
\end{tabular}

Table 4. Part of the matrix used for Paris city example

The Q-analysis of this incidence matrix helps to identify to which profile the smart city is closer.

\subsection{Paris example}

This section presents an example of the application. We selected Paris owing to the amount of available data through the DataCity program (Numa and Ville de Paris, 2015), which lists all of the developed projects. However, although this program is a great source of information, its aim is to enhance innovation: not all of the projects have been implemented in the city, and they may remain at the proof-of-concept stage.

To obtain sufficient data, the projects developed by the DataCity program are considered as real city activities. Furthermore, activities that have been developed by the city and are available on the Paris city website (https://www.paris.fr/) have been added.

In total, there are 40 activities related to Paris from the DataCity program and 15 from the city website. An activity corresponding to the DataCity program itself is also added.

The incidence matrix is constructed by attributing descriptors to each activity (Table 4), resulting in a matrix of 38 rows and 56 columns. This is achieved using the information that is publicly available on the websites, and thus, may not be completely 
representative of the reality. This is particularly the case for the descriptors relating to community buildings and strategic frameworks.

After uploading the matrix in the Hype app, as illustrated in Figure 5, an initial look at the resulting simplices reveals only 35 simplices, meaning that 3 descriptors are not associated with any Paris activity. The simplices with the highest dimension are also represented; that is, the descriptors that are more often linked to the Paris activities. With a dimension of 50, the government is the most involved actor in the activities. This is followed by the development of an application or a service simplex, with a dimension of 48 .

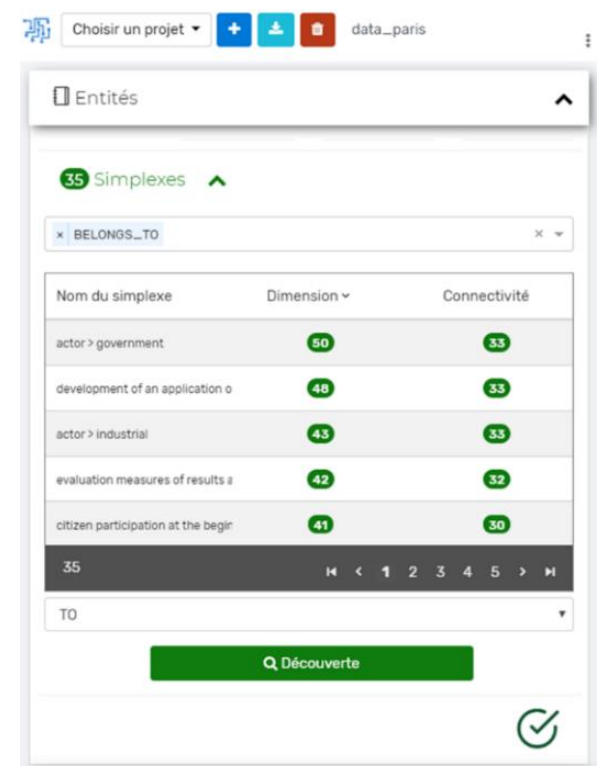

Figure 5. Hype screenshot: simplices, dimensions, and connectivity

An extract of the Q-analysis performed for the highest dimensions yields the following results:

$\mathbf{q}=\mathbf{5 0}$ to $\mathbf{4 9}$ \{actor: government

$\mathbf{q}=\mathbf{4 8}$ to 44 actor: government $\}$; $\{$ development of application or service

$\mathbf{q}=\mathbf{4 3} \quad\{$ actor: government, development of application or service $\} ;$ actor: industrial $\}$

$\mathbf{q}=\mathbf{4 2} \quad\{$ actor: government, development of application or service $\} ;$ actor: industrial $\}$; $\{$ evaluation measures of results or progress $\}$

$\mathbf{q}=\mathbf{4 1} \quad\{$ actor: government, development of application or service, actor: industrial, evaluation measures of results or progress\}; \{citizen participation at beginning\}

$\mathbf{q}=\mathbf{4 0}$ to $\mathbf{3 7}$ \{actor: government, development of application or service, actor: industrial, evaluation measures of results or progress, citizen participation at beginning

$\mathbf{q}=\mathbf{3 6}$ to $\mathbf{1 7}$ \{ actor: government, development of application or service, actor: industrial, evaluation measures of results or progress, citizen participation at beginning, use of public data $\mathbf{q}=\mathbf{1 6}$ to $\mathbf{1 4}$ \{actor: government, development of application or service, actor: industrial, evaluation measures of results or progress, citizen participation at beginning, use of public data, application domain: transport and mobility?

$\mathbf{q}=\mathbf{1 3} \quad$ \{actor: government, development of application or service, actor: industrial, evaluation measures of results or progress, citizen participation at beginning, use of public data, application domain: transport and mobility, no citizen participation \}

$\mathbf{q}=\mathbf{1 2}$ to $\mathbf{1 1}$ \{actor: government, development of application or service, actor: industrial, evaluation measures of results or progress, citizen participation at beginning, use of public data, application domain: transport and mobility, no citizen participation, application domain: energy, application domain: quality of life

As stated previously, the majority of Paris activities involve city administration and the development of an application or a service is prominent: a second actor type is only involved at $q$ dimension 43. The fact that the actor: government and development of an application or a service start to be connected at $\mathrm{q}=43$ simply indicates that there are five activities in which the government is not involved while an application is developed. The government is involved in so many activities that they all tend to be connected, which may occur when the Qanalysis is dominated by one or more simplices (Johnson, 2014). To overcome this, the Q-analysis can be performed by removing the highest-dimension simplices.

The Paris profile can be determined from this Q-analysis. The high dimensions of the government and industrial actors suggest a two-helix model of collaboration.

The evaluation measures emerging at the high dimension of $\mathrm{q}=$ 42 demonstrate an attempt to construct a global strategic framework. The activities leading to the production of a roadmap, a program or an action plan appear at $\mathrm{q}=10$, followed by the creation of workgroups that manage the general course of the smart city development at $\mathrm{q}=8$, which tends to corroborate this attempt and even though they appear at a low dimension.

The citizen participation at the beginning of the activity at $\mathrm{q}=$ 41 suggests quite a strong intent to involve the citizens. At $\mathrm{q}=$ 5, three simplices related to community building also appear: improve understanding of smart city development and the benefits of an ICT-driven approach, citizen participation in the middle, and stimulate user-driven innovation and communityled urban development. As for the strategic framework, an attempt to encourage community building seems to appear.

The use of public data arises at quite a high dimension, which is coherent with the strong government involvement. The main application domains are transport and mobility and, to a lesser extent, energy and quality of life. The other domains appearing at lower dimensions are environment and buildings. The fact that the application domain arrives late after the development of an application or service implies that the domains are relatively wide, which encourages integrated intervention logic.

\subsection{Results}

The Q-analysis performed on the activities developed in Paris helped to determine to which smart city profile it belongs. The analysis revealed that Paris has a two-helix collaboration model with quite integrated intervention logic, with four main 
application domains. Paris also appears to have constructed a strategic framework and attempts to develop community building. Thus, Paris falls within the scope of the techno-socialcentric profile, even though it is not an absolute profile.

However, this profile characterization is only based on information that is publicly available on two websites, and thus, does not include all of the activities developed; if so, the results may have been quite different.

Yet, this techno-social-centric profile aligns with the knowledge obtained from the Paris presentation at the first workshop: a city inclined towards innovation, with a will to involve citizens but without a strong community building policy. Nevertheless, the strategic framework appeared to be more present during the workshops than in the analysis. This can be explained by the fact that more than one third of the activities analyzed originated from the DataCity program, where the aim is clearly to develop an application.

\section{CONCLUSIONS AND PERSPECTIVES}

Many cities implementing activities relating to a smart city face the issue of defining a proper use case. However, the identification of relevant use cases should take into account the city developmental profile. A conceptual model of smart city development has been created to help to identify the city profile. This profile characterization was completed by information in the literature and discussions during the workshops. In parallel, a partial use case methodology for smart cities was proposed, which was adapted from the SGAM. This has led to a smart city model architecture to be used for the use case mapping process.

A smart city profile computation based on simplicial complexes and an example have been presented.

Further analysis could be conducted by determining the opposite relation, whereby the activities are represented as simplices. It may be possible to characterize the panel of activities of a city and how they are grouped together: many groups could suggest significant diversity in the activities. The list of descriptors and activities could also be enriched for a more detailed analysis.

Another approach would be to perform Q-analysis while removing the most connected elements to study the manner in which the other descriptors are connected: for example, a group of descriptors disconnected from the others could imply very specific activity types.

The Hype application could be used as an analytical tool to identify gaps between the actual activities and the goals set by city policies.

Further research could be conducted to detect holes in the simplicial complex structure to enable recommendations for implementing one or more descriptors for a group of activities.

\section{REFERENCES}

Atkin, R., 1977. Combinatorial Connectivities in Social Systems: An Application of Simplicial Complex Structures to the Study of Large Organizations, Interdisciplinary Systems Research. Basel, Birkhäuser Verlag.

Atkin, R., 1974. Mathematical structure in human affairs. Heinemann Educational, London.

Atkin, R., 1972. From cohomology in physics to q-connectivity in social science. International Journal of Man-Machine Studies 4, 139-167. https://doi.org/10.1016/S0020-7373(72)80029-4
CEN-CENELEC-ETSI, 2012. Smart Grid Coordination Group - Smart Grid Reference Architecture Report 2.0.

Cohen, B., Almirall, E., Chesbrough, H., 2016. The City as a Lab: Open Innovation Meets the Collaborative Economy. California Management Review 59, 5-13. https://doi.org/10.1177/0008125616683951

French National Institute for Statistics and Economic Studies (INSEE), 2019. Comparateur de territoire [WWW document] URL https://www.insee.fr/fr/statistiques/zones/1405599 (accessed 4.6.20).

Gottschalk, M., Uslar, M., Delfs, C., 2017. The Use Case and Smart Grid Architecture Model Approach: The IEC 62559-2 Use Case Template and the SGAM applied in various domains, SpringerBriefs in Energy. Springer International Publishing. https://doi.org/10.1007/978-3-319-49229-2

Green, B., 2019. The Smart Enough City: Putting Technology in Its Place to Reclaim Our Urban Future. MIT Press, Cambridge, MA

GWAC, 2008. GridWise® Interoperability Context-Setting Framework.

IEC 62559-2, 2015. Use case methodology - Part 2: Definition of the templates for use cases, actor list and requirements list (Standard). International Electrotechnical Commission, Geneva, Switzerland.

ISO 37105, 2019. Sustainable cities and communities Descriptive framework for cities and communities (Standard). International Standard Organization, Geneva, Switzerland.

Johnson, J., 2014. Hypernetworks in the Science of Complex Systems. Imperial College Press.

Johnson, J., 2012. Cities: Systems of Systems of Systems. Complexity Theories of Cities Have Come of Age 153-172. https://doi.org/10.1007/978-3-642-24544-2_9

Mora, L., Deakin, M., 2019. Untangling Smart Cities: From utopian dreams to innovation systems for a technology-enabled urban sustainability. Elsevier.

Numa, Ville de Paris, 2015. DataCity [WWW document]. Datacity-FR. URL https://www.datacity-fr.numa.co (accessed 4.20.20).

Silva, B.N., Khan, M., Han, K., 2018. Towards sustainable smart cities: A review of trends, architectures, components, and open challenges in smart cities. Sustainable Cities and Society 38, 697-713. https://doi.org/10.1016/j.scs.2018.01.053

van der Wusten, H., 2016. La ville fonctionnelle et les modèles urbains qui lui ont succédé. Exemples d'une pratique politique en train de se globaliser. EchoGéo 36 https://doi.org/10.4000/echogeo.14634

Yin, C., Xiong, Z., Chen, H., Wang, J., Cooper, D., David, B., 2015. A literature survey on smart cities. Science China Information Sciences 58, 1-18. https://doi.org/10.1007/s11432$015-5397-4$ 